\title{
Teresa Sacchet, Silvana Mariano and Cássia Maria Carloto (eds.) Women, Gender and Conditional Cash Transfers: Interdisciplinary Perspectives from Studies of Bolsa Família
}

\author{
New York: Routledge, 2021. 194 pp. €34.99 (pbk). ISBN 9780367251161
}

\author{
Reviewed by: Norman Ginsburg, London Metropolitan University, England
}

\section{https://doi.org/10.1177/02610183211009531c}

Over recent decades Conditional Cash Transfers (CCTs) have become a cornerstone of social policies addressing income poverty across many parts of the Global South, particularly Latin America and sub Saharan Africa. In the 1990s with the fall of the military dictatorship, and the socio-economic stress caused by Structural Adjustment measures, Brazil was one of the pioneers. In 2003 the Workers Party government led by Lula consolidated and expanded earlier programmes into the Bolsa Família (BF - Family Grant). In 2018, 13.7 per cent of families received BF cash, a decline from a peak of 15.9 per cent in 2012 (p. 18). Since the removal of the Workers Party from power in 2016, right wing governments have been cutting the programme. The amount of cash is small, less than 20 per cent of the minimum wage (p. 88) and the total cost of the programme is less than $0.5 \%$ of GDP (p. 88). BF is targeted at mothers, over 90 per cent of recipients are women. BF receipt is conditional on attendance at maternity and child health clinics, on keeping children in school, and on children's participation in 'socialisation and bond strengthening services' (p. 19). This book addresses the impact of BF on women, arguing that it reinforces and prioritises their conventional role as the unpaid carer within households. BF is clearly framed by a 'familism' and 'maternalism' which assumes that government support for mothers and their children also advances women's interests and gender justice. This is essentially paradoxical - clearly women in poverty derive significant material benefits from the programme, but it also strengthens conventional patriarchal roles and oppression in a 'gender trap' (p. 57). This book keeps this paradox to the forefront throughout. Thus the fascinating question of how BF both enhances and undermines 'women's autonomy' is kept in focus.

The book illuminates many critical aspects of BF, particularly the 'race' dimension, the stigmatisation of recipients, the difficulties imposed by conditionalities, and the role of paid/unpaid work. In terms of 'race', there is frequent reference to the fact that non-white women are much more likely to receive BF, which is explored in more detail in a chapter focused on one of the poorest states, Bahia. Here 30 per cent of families receive BF, and 89 per cent of these are non-white households (pp. 67-68). The authors note that these adverse differentials are not addressed by social policy, with the obvious implication that long-established processes of structural and institutional racism are at work, barely challenged by BF and other programmes. Another chapter uses field research in Rio to demonstrate how recipients feel humiliated and subject to surveillance in the administrators' efforts to identify the 'deserving' and the 'undeserving'. Interviews with recipients about their efforts to fulfil conditionalities are reported in another chapter. These involve strenuous juggling of time and responsibilities, which can mitigate against enhancing household income by casual employment. The healthcare conditionalities are particularly problematic because long journeys and long waiting times are often endured to get access to services. While the conditionalities are, of course, well intentioned, in practice inadequate and/or inaccessible public services in education, training, healthcare and child protection can undermine those intentions, particularly in rural communities. 
BF does not make any stipulations about income from paid employment and research findings suggest a very mixed picture. Women in poverty whether receiving BF or not are, unsurprisingly, very unlikely to work in the formal sector of the labour market. They are mostly working casually as domestic servants. BF receipt apparently 'enables women to refuse precarious jobs and sources of exploitation' (p. 99), but, at the same time, beneficiary women are more likely to have a job than poor non-beneficiary women. Perversely BF is in effect subsidising the wages of cleaners and domestic servants for middle class households, similar to the way in which working tax credits subsidise low paying employers in the UK.

This an edited collection made up of two framing chapters, and five others which focus on particular aspects and regions, including some primary research, with ten authors from a range of different universities and disciplines. Inevitably there is some repetition and unevenness, and a lot of unanswered questions. The book is based on a range of primary and secondary research data which is not accessible to readers without Portuguese and so this is very useful. Although there would appear to be an absence of national data on many key aspects, this is an immensely valuable project which succeeds in clarifying the complexities in evaluating such an important programme from a feminist perspective. It shows how BF is shaped by deep structural forces of familism entwined with class, 'race' and gender divisions. It manages to be sociologically critical without giving ammunition to those neoliberals and conservatives who advocate its demise. 